\title{
Choosing important health outcomes for comparative effectiveness research: an updated review and user survey
}

\author{
Sarah L Gorst, Elizabeth Gargon, Paula R Williamson \\ From The Core Outcome Measures in Effectiveness Trials (COMET) Initiative \\ Calgary, Canada. 20-21 May 2015
}

\begin{abstract}
Background
A COS represents an agreed minimum set of outcomes that should be measured and reported in all trials of a specific condition. The COMET (Core Outcome Measures in Effectiveness Trials) initiative aims to collate and stimulate the development and application of COS, by including data on relevant studies within a publically available internet-based resource. In recent years, there has been an interest in increasing the development of COS. Therefore, this study aimed to provide an update of a previous review, and examine the quality of development of COS. A further aim was to understand the reasons why individuals are searching the COMET database.
\end{abstract}

\section{Methods}

A multi-faceted search strategy was followed, in order to identify studies that sought to determine which outcomes/ domains to measure in clinical trials of a specific condition. Additionally, a pop up survey was added to the COMET website, to ascertain why people were searching the COMET database.

\section{Results}

Thirty-two reports relating to 29 studies were eligible for inclusion in the review. There has been an improvement in the description of the scope of a COS and an increase in the proportion of studies using literature/systematic reviews and the Delphi technique. Clinical experts continue to be the most common group involved in developing COS, however patient and public involvement has increased. The pop-up survey revealed the most common

* Correspondence: sgorst@liverpool.ac.uk

Department of Biostatistics, University of Liverpool, Liverpool, UK reasons for visiting the COMET website to be thinking about developing a COS and planning a clinical trial.

\section{Conclusions}

This update demonstrates that recent studies appear to have adopted a more structured approach towards COS development and public representation has increased. However, there remains a need for developers to adequately describe details about the scope of COS, and for greater public engagement. The COMET database appears to be a useful resource for both COS developers and users of COS.

Published: 24 November 2015

doi:10.1186/1745-6215-16-S3-P8

Cite this article as: Gorst et al:: Choosing important health outcomes for comparative effectiveness research: an updated review and user survey. Trials 2015 16(Suppl 3):P8.
Submit your next manuscript to BioMed Central and take full advantage of:

- Convenient online submission

- Thorough peer review

- No space constraints or color figure charges

- Immediate publication on acceptance

- Inclusion in PubMed, CAS, Scopus and Google Scholar

- Research which is freely available for redistribution
() Biomed Central 